\title{
Photosynthetic oxygen flux by Macrocystis pyrifera: a mass transfer model with experimental validation
}

\author{
Amy T. Hansen ${ }^{1, *}$, Miki Hondzo ${ }^{1}$, Catriona L. Hurd ${ }^{2}$ \\ ${ }^{1}$ St Anthony Falls Laboratory, Department of Civil Engineering, University of Minnesota, Minneapolis, Minnesota 55414, USA \\ ${ }^{2}$ Department of Botany, University of Otago, Dunedin 9015, New Zealand
}

\begin{abstract}
The present paper elaborates the development of a mass transfer model to determine rates of photosynthetic oxygen flux from the giant kelp Macrocystis pyrifera in a moving fluid. The model can be used to calculate local dissolved oxygen flux, blade-averaged oxygen flux and daily average net primary productivity for a kelp forest. Predicted rates of photosynthetic oxygen flux agree well with previously reported direct measurements. This model was derived from the fundamental principles of conservation of mass and momentum over a flat plate using an integral method approach and is applicable in laminar, transitional and turbulent flows. It predicts oxygen flux as an explicit function of fluid flow conditions above the kelp blade. Experimental velocity profiles and dissolved oxygen concentration profiles, measured under a range of fluid flow conditions, followed power-law scaling and demonstrated local similarity between oxygen and velocity distribution within the boundary layers above the kelp blade. The proposed model provides a useful tool for estimating rates of photosynthesis with minimal data collection.
\end{abstract}

KEY WORDS: Photosynthesis · Mass transfer $\cdot$ Macrocystis pyrifera $\cdot$ Model $\cdot$ Dissolved oxygen

\section{INTRODUCTION}

Macrocystis pyrifera, commonly known as giant kelp, forms large, highly productive forests in temperate coastal waters worldwide (Graham et al. 2007). It typically grows in near-shore, subtidal regions that can be either current or wave dominated (e.g. Gaylord et al. 2004). At reported growth rates of $2 \mathrm{~kg}$ dry mass $\mathrm{m}^{-2}$ $\mathrm{yr}^{-1}$ and a standing biomass of 10 fronds $\mathrm{m}^{-2}$ (Rosman et al. 2007, Reed et al. 2008), M. pyrifera heavily influences local concentrations of dissolved gases and water velocity, creating an important microhabitat that maintains biodiversity (Dayton 1985, Steneck et al. 2002). Within M. pyrifera forests, velocities have been reported to be 25 to $33 \%$ of those measured in adjacent open waters (Fram et al. 2008).

Experimental studies have demonstrated that water motion can modify the rate of photosynthesis, and thus primary productivity, by Macrocystis pyrifera, through 3 distinct processes (Wheeler 1980, Gerard 1982, Hurd et al. 1996). Low nitrate concentrations, such as those that occur in the summer, coupled with low seawater velocities, have been shown in both field and laboratory investigations to decrease photosynthesis (Jackson 1977, Zimmerman \& Kremer 1986, Hepburn \& Hurd 2005). Dissolved inorganic carbon (DIC) limitation of photosynthesis can occur at free-stream velocities $<7 \mathrm{~cm} \mathrm{~s}^{-1}$ with water DIC concentrations under $6 \mu \mathrm{mol} \mathrm{l}^{-1}$ (Wheeler 1980). DIC limitation is thought to result from either boundary layer resistance or from the buildup of the photosynthetic waste product $\mathrm{OH}^{-}$ in the boundary layer (Maberly 1990, Gonen et al. 1993, Hurd 2000). Recent research suggests that reduced efflux of dissolved oxygen (DO) from the blade surface may increase photorespiration and thus lower photosynthetic rates (Mass et al. 2010).

The influence of water motion on both the supply of dissolved nutrients and the removal of metabolic byproducts at the blade surface is referred to as mass transfer (e.g. Hurd 2000). During photosynthesis, local 
gradients of DIC, dissolved nutrients, and DO form concentration boundary layers adjacent to the surface of kelp blades, due to the difference in the freestream water concentration and the concentration at the blade surface. Similarly, a velocity gradient is formed by the stress generated by fluid motion near the blade surface (e.g. Kays et al. 2005). When reduced water motion limits mass transport, the supply of DIC and dissolved nutrients to the blade surface is replenished more slowly than the blade consumes them, and photosynthetic rates are limited by mass transfer processes. The occurrence of mass transfer limitation of photosynthesis depends on the relative rates of kelp intracellular metabolic processes to the water-side mass transfer processes (Sanford \& Crawford 2000). At higher velocities, intracellular processes are often more limiting to photosynthesis than are mass transfer processes (Enriquez \& RodriguezRoman 2006).

Estimating rates of photosynthesis in situ continues to challenge researchers. Common methods include measuring electron transport rates (ETR) or measuring the evolution of DO. A direct measurement of the photosynthetic rate can be made by placing a tissue segment in an enclosed chamber and recording the change in bulk water DO concentration, which is not practical in situ without altering the flow conditions (e.g. Wheeler 1980, Koch 1994). While ETR measurements can be made relatively easily in situ, laboratory experiments have demonstrated that they are accurate predictors of photosynthetic flux only under conditions where light is limiting (Longstaff et al. 2002). Alternatively, DO concentration profiles, measured with micro-sensors, have been used with Fick's Law to estimate photosynthetic flux (Sand-Jensen et al. 1985, Miller \& Dunton 2007, Nishihara \& Ackerman 2007). This method preserves variations along the blade, but the accuracy is strongly affected by the function used to describe the concentration profile, and results vary depending on how the concentration is described mathematically (Hondzo et al. 2005, Nishihara \& Ackerman 2006). Additionally, relevant information about the momentum transfer is not explicitly incorporated into the estimation.

Previous efforts to model photosynthetic flux using mass transfer theory have assumed fully turbulent flow conditions and used empirical constants to adjust for disagreements between field measurements and model predictions (e.g. Koch 1994, Falter et al. 2004, Cornelisen \& Thomas 2009). Although this may be justified for applications in habitats such as coral reefs, measured velocities in the interior of moderate-sized Macrocystis pyrifera forests have been reported between 0.1 and $5 \mathrm{~cm} \mathrm{~s}^{-1}$ (Gaylord et al. 2007, Fram et al. 2008), corresponding to laminar or transitional flow conditions. Laboratory experiments have demonstrated through flow-visualization studies that flow unsteadiness around kelp blades starts around $2 \mathrm{~cm} \mathrm{~s}^{-1}$ (Wheeler 1980, Hurd \& Stevens 1997). Flow that exhibits unsteadiness, but has not yet developed into full turbulence, which occurs around Reynolds numbers of $10^{5}$ for flow over a smooth flat plate, is termed transitional and is characterized by intermittent bursts of eddies (e.g. Schlichting 1979). At the velocities experienced inside a kelp bed, the assumption of fully turbulent flow would predict a thinner boundary layer, a higher mass flux rate, and earlier saturation of mass transfer controlled flux than what occurs under the more realistic transitional flow.

Fluid motion has been reported to mediate photosynthesis. Fluid flow conditions within a kelp forest span laminar, transitional, and turbulent flow regimes. The objective of the present study was to measure and model the effect of fluid motion on kelp photosynthesis over the velocity range typically reported within kelp forests. The model has been applied to experimentally measured DO and velocity profiles above single blades of Macrocystis pyrifera to estimate local surface DO flux, blade-averaged flux, and entire forest net primary productivity (NPP).

\section{METHODS}

Model derivation. The proposed model was derived from the laws of conservation of mass and momentum applied to control volumes (CV) extending from a kelp blade surface to the edge of the concentration boundary layer (CBL) and of the momentum boundary layer (MBL). It was assumed that the DO concentration at the blade surface, $C_{\mathrm{s}}\left(\mathrm{mg} \mathrm{l}^{-1}\right)$, the free-stream DO concentration, $C_{\infty}\left(\mathrm{mg} \mathrm{l}^{-1}\right)$, and the free-stream velocity, $u_{\infty}$ $\left(\mathrm{m} \mathrm{s}^{-1}\right)$, were constant. We further assumed the blade was hydrodynamically smooth; requiring that for typical velocities within a kelp bed $\left(u_{\infty}<5 \mathrm{~cm} \mathrm{~s}^{-1}\right)$ the maximal blade corrugation height is $<0.25 \mathrm{~cm}$.

Under the above assumptions, the integral form of conservation of momentum into and out of a control volume of height $\delta(\mathrm{m})$ and length $\mathrm{dx}(\mathrm{m})$ was expressed as:

$$
-\tau_{s}=\frac{\mathrm{d}}{\mathrm{d} x}\left(\int_{0}^{\delta} \rho u^{2} \mathrm{~d} y\right)-u_{\infty} \frac{\mathrm{d}}{\mathrm{d} x}\left(\int_{0}^{\delta} \rho u \mathrm{~d} y\right)
$$

where $x(m)$ is distance in the stream-wise direction, $y(\mathrm{~m})$ is the vertical distance from the blade surface, $u\left(\mathrm{~m} \mathrm{~s}^{-1}\right)$ is the stream-wise velocity, $\tau_{\mathrm{s}}\left(\mathrm{kg} \mathrm{m}^{-1} \mathrm{~s}^{-2}\right)$ is the surface shear stress, and $\rho\left(\mathrm{kg} \mathrm{m}^{-3}\right)$ is the water density (Fig. 1). All velocity terms are time-averaged.

Following a similar approach to that used with conservation of momentum, conservation of DO mass was 
evaluated using the mass flux into and out of a control volume of height $\Delta(\mathrm{m})$ with width $\mathrm{d} x$ (Fig. 1). In integral form, conservation of DO mass is:

$$
J_{s}=\frac{\mathrm{d}}{\mathrm{d} x}\left(\int_{0}^{\Delta} \rho u\left(C-C_{\infty}\right) \mathrm{d} y\right)
$$

where $J_{\mathrm{s}}\left(\mathrm{mg} \mathrm{m}^{-2} \mathrm{~s}^{-1}\right)$ is the DO flux at the kelp blade surface and $C\left(\mathrm{mg} \mathrm{l}^{-1}\right)$ is the DO concentration. All concentrations are time-averaged.

We used power functions to represent the velocity and DO profiles respectively:

$$
\begin{gathered}
\frac{u}{u_{\infty}}=\left(\frac{y}{\delta}\right)^{1 / n} \\
\frac{C_{s}-C(y)}{C_{s}-C_{\infty}}=\left(\frac{y}{\Delta}\right)^{1 / n}
\end{gathered}
$$

where $n$ is a constant. The major assumption, resulting in the same exponential dependency on $y \delta^{-1}$ in Eq. (3) and $y \Delta^{-1}$ in Eq. (4), was that the shape of the dimensionless concentration profile and dimensionless velocity profile were locally similar. The right sides of Eqs. (1 \& 2) were integrated using Eqs. ( 3 \& 4). To evaluate $\tau_{\mathrm{s}}$ we wrote Eq. (3) in terms of the commonly used dimensionless variables $u^{+}$and $y^{+}$, where $u^{+}=u u_{*}{ }^{-1}, y^{+}$ $=y u_{*} v^{-1}, v\left(\mathrm{~m}^{2} \mathrm{~s}^{-1}\right)$ is the kinematic viscosity, and $u_{*}$ $\left(\mathrm{m} \mathrm{s}^{-1}\right)$ is the shear velocity. Eq. (3) was rearranged to the form:

$$
u^{+}=a_{c}\left(y^{+}\right)^{1 / n}
$$

where $a_{\mathrm{C}}=\left(u_{\infty} u_{*}^{-1}\right)\left[v\left(u_{*} \delta\right)^{-1}\right]^{1 / n}$ is typically treated as an empirical constant (Schlichting 1979). Following the procedure developed by Reynolds to evaluate $\tau_{\mathrm{s}}$ in Eq. (1), the ratio of $\tau$ at $y$ to $\tau$ at $\delta$ was evaluated and then used with the mixing layer analogy for shear stress in a turbulent flow, $\tau / \rho=\left[v+\varepsilon_{\mathrm{m}}\right] \partial u / \partial y$ to solve for $\left[v+\varepsilon_{m}\right]$, where $\varepsilon_{m}\left(m^{2} s^{-1}\right)$ is the eddy diffusivity for momentum (Kays et al. 2005). For a high Schmidt number $\left(\mathrm{Sc}=v D^{-1}\right)$ fluid, such as seawater, where $D$ is the molecular diffusion coefficient, the turbulent Schmidt number $\left(S c_{\mathrm{T}}=\varepsilon_{\mathrm{m}} D_{\mathrm{T}}^{-1}\right)$, where $D_{\mathrm{T}}\left(\mathrm{m}^{2} \mathrm{~s}^{-1}\right)$ is the turbulent mass diffusion coefficient, is approximately 1 near a surface (Bird et al. 2002, Kays et al. 2005). Using $S c_{\mathrm{T}}=1$ with $v \gg \varepsilon_{\mathrm{m}}$ within the concentration boundary layer, the sum of the $D$ and $D_{\mathrm{T}}$ was expressed in terms of $\left[v+\varepsilon_{\mathrm{m}}\right]$ as:

$$
\left[D+D_{\mathrm{T}}\right] \approx S C^{-1}\left[v+\varepsilon_{m}\right]
$$

This expression was then substituted into Fick's First Law, $J=-\left[D+D_{\mathrm{T}}\right] \frac{\partial C}{\partial y}$, and evaluated at the blade surface. The final expression for local surface oxygen flux is:

$$
J_{S}(x)=A S C^{-\left(\frac{n+1}{n+2}\right)} \operatorname{Re}_{x}^{-\left(\frac{2}{n+3}\right)} u_{\infty}\left(C_{s}-C_{\infty}\right)
$$

where $A$ is the dimensionless constant:

$$
A=\left(\frac{n}{a_{c}^{n}(n+3)(n+2)}\right)^{\left(\frac{2}{n+3}\right)}
$$

A detailed derivation of the model can be found in Appendix 1.

Eq. (7) is an analytical solution to the conservation equations (Eqs. $1 \& 2$ ), with the velocity and DO profiles approximated by a power function (Eqs. $3 \& 4$ ). It contains 2 model parameters, $a_{\mathrm{c}}$ and $n$.

To estimate the blade-averaged DO flux, $\bar{J}_{\mathrm{s}, \text { blade }}$ (mol $\mathrm{cm}^{-2} \mathrm{~h}^{-1}$ ), Eq. (7) can be integrated over the area of the blade using the blade length $L(\mathrm{~m})$ and the blade width $B(x)(m)$, where $x$ is the distance from the stipe. The blade-averaged DO flux is then defined as:

Light

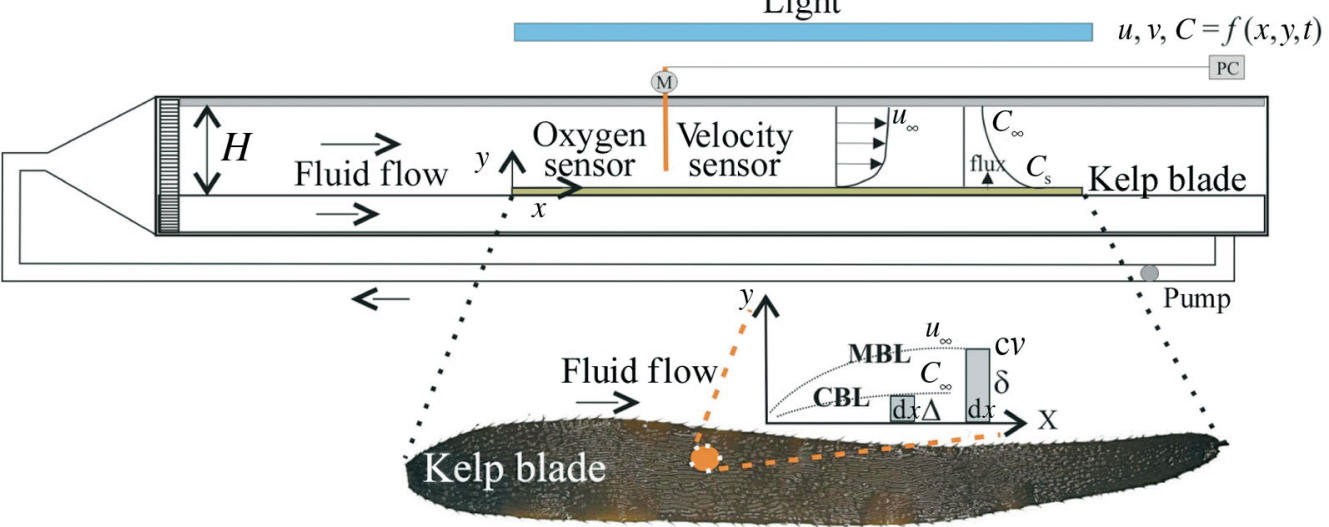

Fig. 1. Schematic representation of the mass transfer system above a kelp blade within a flume setup. Filtered seawater was recirculated with an adjustable motor-driven propeller through the $46 \mathrm{l}$ flume (test section dimensions: $0.2 \mathrm{~m}$ width, $0.15 \mathrm{~m}$ height, $0.85 \mathrm{~m}$ length). The control volumes used for the derivation of the integral forms of conservation of momentum, length $\mathrm{d} x$ and height $\delta$, and for the conservation of dissolved oxygen, length $\mathrm{d} x$ and height $\Delta$ are shown. $H$ : height of the channel; CBL: concentration boundary layer; MBL: momentum boundary layer; CV: control volume; parameter abbreviations, see 'Methods' section 


$$
\bar{J}_{\mathrm{s}, \text { blade }}=\frac{2}{A_{s}} \int_{0}^{L} B(x) J_{s}(x) \mathrm{d} x
$$

where $A_{\mathrm{s}}\left(\mathrm{m}^{-2}\right)$ is the total blade area.

Flux estimation for no flow condition. When the water velocity is zero DO is transported through the water by pure diffusion. If the experimental sample time is less than that required for the DO gradient to reach equilibrium, concentration variation with time must be included in the governing equation and is given by (e.g. Cussler 1984):

$$
\frac{\partial C}{\partial t}=D \frac{\partial^{2} C}{\partial y^{2}}
$$

The exact solution to Eq. (10), evaluated at the blade surface is:

$$
J_{s}=\sqrt{D / t \pi}\left(C_{s}-C_{\infty}\right)
$$

where $t(\mathrm{~s})$ is the elapsed time.

Sample collection and preparation. Macrocystis pyrifera blades were collected between May and July 2007, near Harrington Point $\left(45^{\circ} 47^{\prime} 03.5^{\prime \prime} \mathrm{S}\right.$, $\left.170^{\circ} 43^{\prime} 22.7^{\prime \prime} \mathrm{E}\right)$ at the mouth of Otago Harbour, Dunedin, New Zealand, a site that is sheltered from waves and affected by strong tidal currents (Hepburn \& Hurd 2005). Sample blades were selected to be similar distances along the fronds so that the ages of the blades were similar. Blades were cut at the stipepneumatocyst junction, placed in an insulated container filled with seawater and transported back to the laboratory, within $2 \mathrm{~h}$. At the laboratory, blades were stored in open, aerated plastic bins containing filtered (Whatman GF/C) seawater in a Conviron Model E15 temperature-controlled room kept at $12^{\circ} \mathrm{C}$ with a $12 \mathrm{~h}$ light:12 h dark cycle. An underwater pulse amplitude modulated chlorophyll fluorometer (Diving PAM, Heinz Walz $\mathrm{GmbH}$ ), with $650 \mathrm{~nm}$ maximum emission wavelength and default internal gain and intensity settings, was used to select experimental blades based on measured fluorescent yield $\left(F_{\mathrm{v}}: F_{\mathrm{m}}\right)$ (Maxwell \& Johnson 2000).

Laboratory experiments. Experiments were conducted in a $46 \mathrm{l}$ flume, described fully by Hurd et al. (1994) (Fig. 1). Briefly, filtered seawater was recirculated through a flume consisting of a small motordriven propeller, entrance diffusers, and a test section of $0.2 \mathrm{~m}$ width, $0.15 \mathrm{~m}$ height, and $0.85 \mathrm{~m}$ length. A photon flux density of $130 \mu \mathrm{mol}$ photons $\mathrm{m}^{-2} \mathrm{~s}^{-1}$ at the blade's surface, chosen to facilitate comparison with Wheeler (1980), was provided by an overhead SONTARGO 400 light. Water temperature was monitored, but not controlled. The physical water property $v$ was calculated based on a salinity of $35 \mathrm{~g} \mathrm{l}^{-1}$ and the average temperature for each experiment (see Table 2). The value used for the molecular diffusion coefficient
$D$ was $1.7 \times 10^{-5} \mathrm{~cm}^{2} \mathrm{~s}^{-1}$ (Wheeler 1980). For each replicate, an individual kelp blade was attached to a flat plate and placed in the flume after removing the pneumatocyst.

Velocity was measured with an acoustic Doppler velocimeter ( $\mu \mathrm{ADV}$; Sontek YSI Inc.) at $50 \mathrm{~Hz}$ sampling frequency, for $1 \mathrm{~min}$ per sample location. Velocity measurements were made every $0.2 \mathrm{~cm}$ within $3 \mathrm{~cm}$ of the blade and then every $1 \mathrm{~cm}$. The vertical $\mu \mathrm{ADV}$ position was adjusted manually with $0.1 \mathrm{~cm}$ accuracy. Velocity profiles were located at the blade centerline, at a distance of $10 \mathrm{~cm}$ from the front of the blade, extending from the blade surface. Shear velocity, $u_{*}\left(\mathrm{~m} \mathrm{~s}^{-1}\right)$, used in the determination of $a_{\mathrm{c}}$ from experimental data, was estimated in 3 ways: (1) from the slope of the timeaveraged velocity data in the log-law in the region, using the Law of the Wall, $u^{+}=\frac{1}{\kappa} \ln y^{+}+B$, where $\kappa$ is the von Karman's constant 0.41 and $B$ is a constant; (2) with the 2-dimensional momentum equation for turbulent flow with boundary layer approximations,

$\frac{\tau}{\rho}=-\overline{u^{\prime} v^{\prime}}+v \frac{\mathrm{d} u}{\mathrm{~d} y}=u_{*}^{2}(1-y / H)$, where $\overline{\bar{u}^{\prime} v^{\prime}}\left(\mathrm{m}^{2} \mathrm{~s}^{-2}\right)$ is the Reynolds stress and $H(\mathrm{~m})$ is the height of the channel (e.g. Nezu \& Rodi 1986); and (3) from the definition of shear velocity $u_{*} \equiv \sqrt{\left.v \frac{\mathrm{d} u}{\mathrm{~d} y}\right|_{y=0}}$.

DO concentration was measured using an optical oxygen micro-sensor (Microx TX2-A) with a maximum tip diameter of $50 \mu \mathrm{m}$ (PreSens Precision Sensing $\mathrm{GmbH}$ ). DO measurements were made every $0.05 \mathrm{~mm}$ near the blade surface then every $0.25 \mathrm{~mm}$. The vertical sensor position was controlled using 2 mechanical stages with a positional accuracy of $0.001 \mathrm{~mm}$ for measurements within $5 \mathrm{~mm}$ of the blade surface and of $0.1 \mathrm{~mm}$ for measurements further from the blade. The location of the blade surface was determined by lowering the oxygen probe, using the precision stage, until contact of the probe with the blade was confirmed visually. Then, to assure that the probe was not pushing into the blade tissue, the probe was retracted, again with the precision stage, until the DO concentration reading dropped. This was repeated until the location of the kelp surface was determined. Percent oxygen saturation was measured for 1 min per sample location at a sampling rate of $1 \mathrm{~Hz}$ with temperature compensation enabled. Atmospheric pressure, used to convert DO measurements from percent saturation to $\mathrm{mg} \mathrm{l}^{-1}$, was obtained from www.metservice.co.nz, as measured at the Dunedin airport $20 \mathrm{~km}$ away at $3 \mathrm{~h}$ intervals. Sensors were calibrated each day before measurements using a sodium sulfite solution $\left(\mathrm{Na}_{2} \mathrm{SO}_{3}\right)$ and water-saturated air. DO concentration profiles were taken for each of the 5 replicate blades at average free-stream velocities of $0.0,2.7,4.6$, and 
$9.8 \mathrm{~cm} \mathrm{~s}^{-1}$. To minimize the effect of the $1 \mathrm{~mm}$ tall kelp surface corrugations, measurements were always taken above the apex of a ridge (Hurd \& Pilditch 2011).

\section{RESULTS}

\section{Flow conditions}

Experimental flow data were utilized to determine shear velocity and power functions for the mean velocity profiles. The time-averaged experimental dimen-

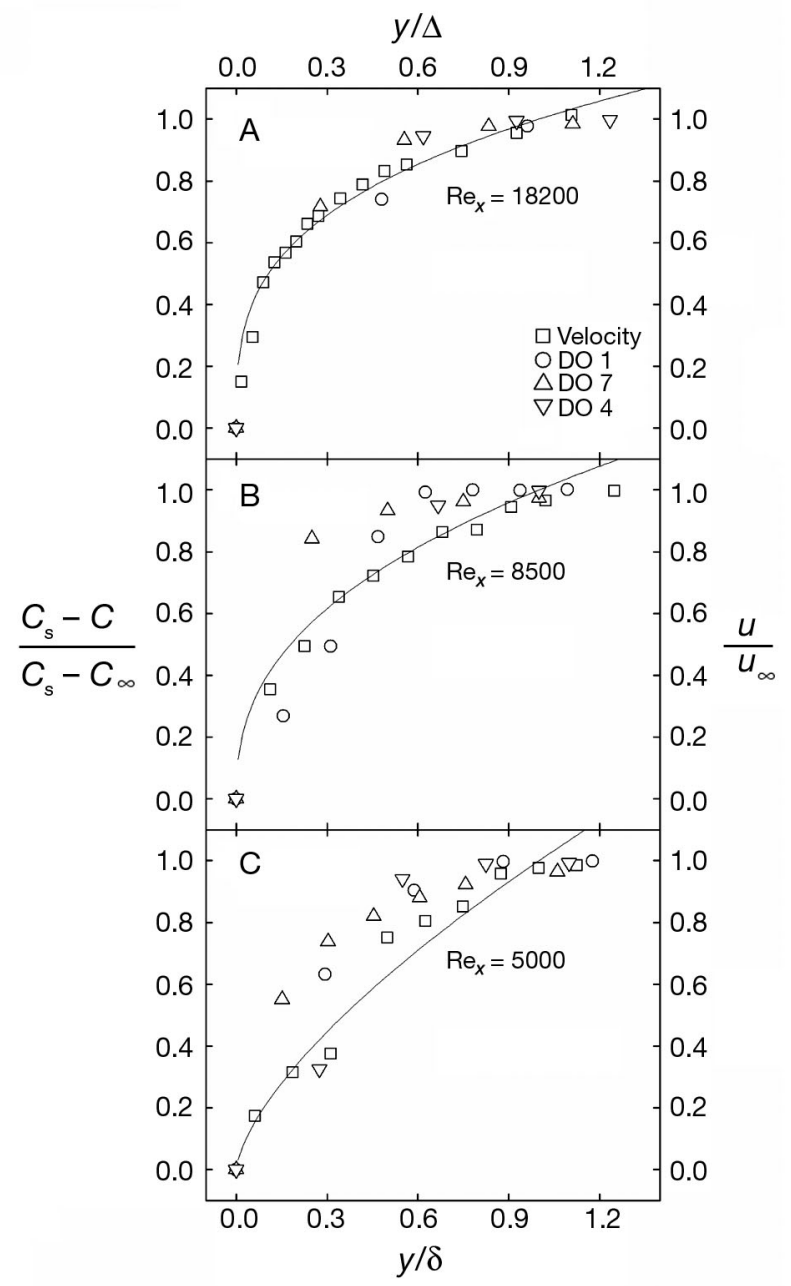

Fig. 2. Comparison between experimental velocity and concentration profile data and power functions used in the model. The 3 panels represent all data for a given Reynolds number: (A) $\operatorname{Re}_{x}=18200$, (B) $\operatorname{Re}_{x}=8500$, and (C) $\operatorname{Re}_{x}=5000$. The distance from the blade, $y_{1}$ is made nondimensional with the boundary layer thicknesses $\delta$ for velocity profiles and $\Delta$ for concentration profiles. Velocity, $u$, is normalized with the free-stream velocity, $u_{\infty}$. Dissolved oxygen (DO) concentration, $C$, is made dimensionless using the surface concentration, $C_{\mathrm{s}}$ and the free-stream concentration, $C_{\infty}$. All variables are time-averaged
Table 1. Flow characteristics based on experimental velocity profiles above Macrocystis pyrifera blades. Free-stream velocity, $u_{\infty}$ is the average velocity above the momentum boundary layer. Shear velocity, $u_{*}$, was calculated using the slope of the log-law and the Reynolds stresses for $\mathrm{Re}_{x}=8500$ and 18200, then averaged. The definition of shear velocity was used to calculate shear velocity for $\operatorname{Re}_{x}=5000$. The momentum boundary layer thickness, $\delta$, and the exponent $n$ for the power function to the data are reported with the $\mathrm{R}^{2}$ for the nonlinear regression, where $m$ is the number of data points in the regression

\begin{tabular}{|lcccccr|}
\hline $\operatorname{Re}_{x}$ & $\begin{array}{c}u_{\infty} \\
\left(\mathrm{cm} \mathrm{s}^{-1}\right)\end{array}$ & $\begin{array}{c}u_{*} \\
\left(\mathrm{~cm} \mathrm{~s}^{-1}\right)\end{array}$ & $\begin{array}{c}\delta \\
(\mathrm{cm})\end{array}$ & $n$ & $\mathrm{R}^{2}$ & $m$ \\
\hline 5000 & 2.71 & 0.16 & 1.6 & 1.49 & 0.96 & 8 \\
8500 & 4.59 & 0.30 & 2.45 & 2.48 & 0.97 & 10 \\
18200 & 9.83 & 0.87 & 5.5 & 3.23 & 0.96 & 14 \\
\hline
\end{tabular}

sionless velocity data were fit to Eq. (3) to determine $n$ and $\delta$ (Fig. 2). The experimental free-stream velocity, $u_{\infty}$, ranged from 2.71 to $9.83 \mathrm{~cm} \mathrm{~s}^{-1}$ (Table 1). For all velocities, power function approximations agreed well with the experimental data $\left(\mathrm{R}^{2} \geq 0.96\right.$; Table 1$)$.

Shear velocity estimates using the log-law method and the Reynolds stresses method agreed within 3\% for both $\operatorname{Re}_{X}=8500$ and $\operatorname{Re}_{X}=18200$. An average of these 2 results was used for the model (Table 1). Insufficient resolution in the velocity profile near the blade surface prevented estimating $u_{*}$ using the gradient near the blade surface for $\operatorname{Re}_{X}=8500$ and $\operatorname{Re}_{X}=18200$. Velocity profile data for $\mathrm{Re}_{x}=5000$ did not have resolvable Reynolds stresses or a clear log-law region, but they did have sufficient resolution near the blade in order to estimate $u_{*}$ with the velocity gradient (Table 1). Calculations of $u_{*}$ from experimental data agreed with model-estimated values within $12 \%$. The parameters $u_{*}, u_{\infty}, \delta$, and $n$ were used to calculate $a_{\mathrm{C}}$ from experimental data according to Eq. (5).

The model parameters $n$ and $a_{C}$ were graphed against $\operatorname{Re}_{X}$ (Fig. 3). Previously reported values for $10^{5}<\operatorname{Re}_{x}<2.5 \times 10^{6}$ (Burmeister 1993) were included in the graph along with the exact Blasius solution for a laminar flow, where $n=1, a_{C}=0.59$, and $\operatorname{Re}_{x}=1850$. All graphed points for $\operatorname{Re}_{X}>10^{3}$ were used to generate the functional relationships to be used for model parameter determination. The resulting equations are: $n=$ $1.29 \ln \left(\operatorname{Re}_{x}\right)-9.08\left(R^{2}=0.97\right)$ and $a_{C}=1.54 \ln \left(R_{x}\right)-11$ $\left(\mathrm{R}^{2}=0.90\right)$. For $\mathrm{Re}_{x}<2000$, the parameters were fixed to $n=1$ and $a_{\mathrm{C}}=0.59$.

\section{Dissolved oxygen}

Well-resolved DO profiles were attained for 3 of the 5 replicate blades. The boundary layers of the other 2 


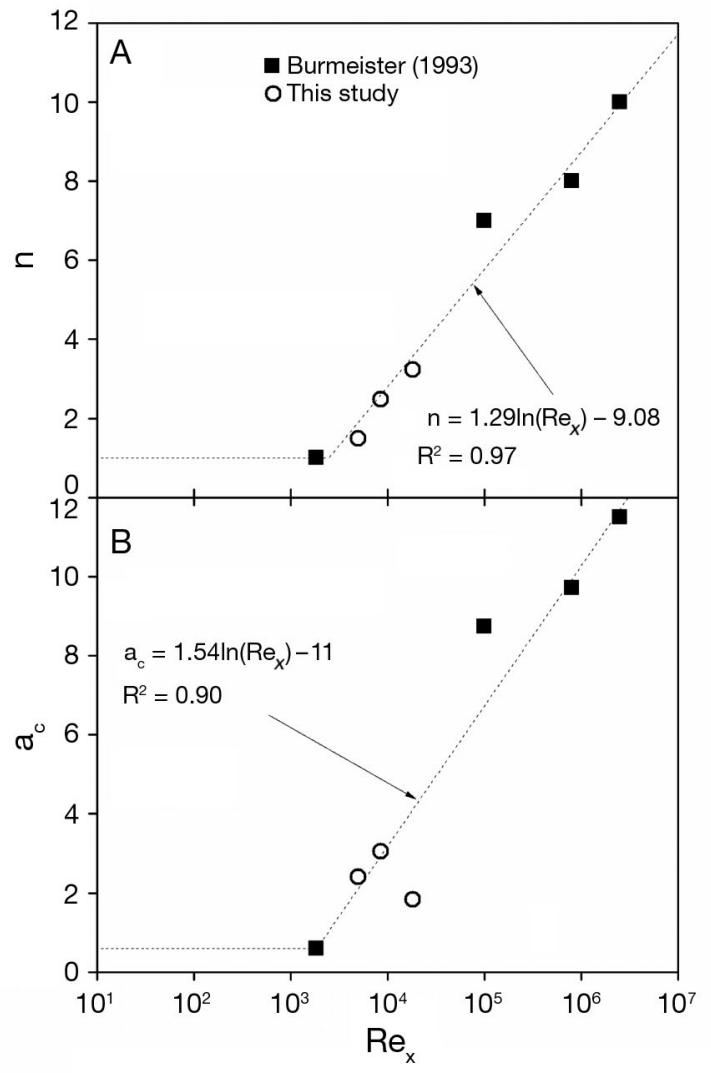

Fig. 3. Relationship between local Reynolds number, $\operatorname{Re}_{x}$ and the parameters $a_{\mathrm{c}}$ and $n$ used in the model. Symbols represent calculated values from experimental measurements in the present study (O) and reported values ( $\mathbf{\square}_{\text {; }}$ Burmeister 1993).

The dashed line is the best fit regression for these points

blades fell below the second measurement point and could not be modeled. DO concentration boundary layers were typically on the order of $1 \mathrm{~mm}$ thickness. Due to a lack of experimental data in the concentration boundary layers at higher velocities, the concentration boundary layer thickness, $\Delta(\mathrm{m})$, could not be determined from Eq. (4), as was done with the velocity data and Eq. (3). Instead, the experimental concentration profiles were fit with a hyperbolic tangent function, and $\Delta$ was determined as the distance at which $C(\Delta)=$ $1.01 C_{\infty}$ a method that compared favorably to integrated DO flux measurements (Nishihara \& Ackerman 2007). Experimental measurements of $C_{\mathrm{s},} C_{\infty}$ and $\Delta$ are reported (Table 2). Experimental profiles are shown with modeled functions (Fig. 2). The collapse of the experimentally measured velocity and DO concentration data onto 1 curve (Fig. 2) validates the model assumption of similarity between these boundary layers. Although boundary layer DO profiles were not always well resolved, $C_{\mathrm{s}}$ was successfully measured for all 5 blades. For 4 of the 5 replicate blades, $C_{\mathrm{s}}$ decreased with increasing $\operatorname{Re}_{x}$ (Fig. 4).
Table 2. Experimental dissolved oxygen (DO) concentration data used in a flux model for 5 replicate blades. Surface DO concentration, $C_{\mathrm{s}}$, was measured at the Macrocystis pyrifera blade surface. Free-stream concentration, $C_{\infty}$ is the average concentration in the free-stream water above the boundary layer. The concentration boundary layer thickness, $\Delta$, was determined as $C(\Delta)=1.01 C_{\infty}$ after fitting the entire DO concentration profile to a hyperbolic tangent; it is not used explicitly in the flux model (NA: not applicable)

\begin{tabular}{|lccccc|}
\hline $\mathrm{Re}_{X}$ & $\begin{array}{c}C_{\mathrm{s}} \\
\left(\mathrm{mg} \mathrm{l}^{-1}\right)\end{array}$ & $\begin{array}{c}C_{\infty} \\
\left(\mathrm{mg} \mathrm{l}^{-1}\right)\end{array}$ & $\begin{array}{c}\Delta \\
(\mathrm{cm})\end{array}$ & $\begin{array}{c}T \\
\left({ }^{\circ} \mathrm{C}\right)\end{array}$ & $\begin{array}{c}\bar{J}_{\mathrm{s}, \text { blade }} \\
\left(\mu \mathrm{mol} \mathrm{cm}{ }^{-2} \mathrm{~h}^{-1}\right)\end{array}$ \\
\hline Blade 1 & & & & & \\
0 & 21.98 & 9.99 & $\mathrm{NA}$ & 12.2 & 0.08 \\
5000 & 23.33 & 9.64 & 0.085 & 11.3 & 0.15 \\
8500 & 20.39 & 9.95 & 0.160 & 11.4 & 0.20 \\
18200 & 18.46 & 9.78 & 0.052 & 11.3 & 0.25 \\
Blade 4 & & & & & \\
0 & 44.79 & 10.71 & $\mathrm{NA}$ & 11.6 & 0.38 \\
5000 & 40.81 & 10.50 & 0.091 & 11.7 & 0.33 \\
8500 & 31.57 & 10.37 & 0.075 & 11.8 & 0.40 \\
18200 & 27.90 & 10.48 & 0.081 & 12.1 & 0.51 \\
Blade 6 & & & & & \\
0 & 41.52 & 10.36 & $\mathrm{NA}$ & 17.0 & 0.47 \\
5000 & 49.19 & 9.90 & 0.032 & 16.7 & 0.43 \\
8500 & 45.48 & 9.97 & 0.033 & 16.6 & 0.68 \\
18200 & 22.77 & 10.03 & 0.028 & 16.5 & 0.37 \\
Blade 7 & & & & & \\
0 & 31.29 & 9.93 & $\mathrm{NA}$ & 16.1 & 0.15 \\
5000 & 29.32 & 9.55 & 0.033 & 15.7 & 0.22 \\
8500 & 31.57 & 9.60 & 0.020 & 15.5 & 0.42 \\
18200 & 30.27 & 9.57 & 0.018 & 15.5 & 0.60 \\
Blade 8 & & & & & \\
0 & 37.82 & 10.74 & $\mathrm{NA}$ & 12.5 & 0.24 \\
5000 & 29.28 & 9.56 & 0.038 & 12.5 & 0.21 \\
8500 & 32.52 & 9.62 & 0.051 & 12.7 & 0.44 \\
18200 & 23.69 & 9.71 & 0.047 & 12.8 & 0.41 \\
& & & & & \\
\hline
\end{tabular}

\section{Local surface oxygen flux}

The model was applied to each blade for non-zero velocities using the parameters $n$ and $a_{c}$ generated from the velocity profiles and the measured values of $u_{\infty}, C_{\mathrm{s}}$ and $C_{\infty}$ for individual blades. Water temperature varied by $<0.6^{\circ} \mathrm{C}$ across experiments for an individual blade (Table 2). $\Delta$ was not a variable in the final expression for $J_{\mathrm{s}}(x)$ (Eq. 7) and was not used in calculations. Surface flux in the absence of advection $\left(u_{\infty}=0\right)$ was calculated using Eq. (11). Predicted local DO flux from the kelp blades (5 replicates) ranged from $0.27 \pm$ $0.16 \mu \mathrm{mol} \mathrm{O} \mathrm{Cm}^{-2} \mathrm{~h}^{-1}$ for $\mathrm{Re}_{\mathrm{x}}=0$ to $0.80 \pm 0.25 \mu \mathrm{mol} \mathrm{O}$ $\mathrm{cm}^{-2} \mathrm{~h}^{-1}$ for $\mathrm{Re}_{x}=$ 18200. $J_{\mathrm{s}}(x)$ increased with $\mathrm{Re}_{x}$ (Fig. 5). A 1-way ANOVA was conducted to compare the effect of $\operatorname{Re}_{x}$ on $J_{\mathrm{s}}(x)$. There was a significant effect of $\operatorname{Re}_{x}$ on $J_{\mathrm{s}}(x)$ for the $4 \operatorname{Re}_{x}$ conditions $[F(3,16)=10.08$, $\mathrm{p}=0.001]$. Post hoc Tukey's honestly significant difference tests indicated that $J_{\mathrm{s}}(x)$ for $\mathrm{Re}_{x}=18150$ was 


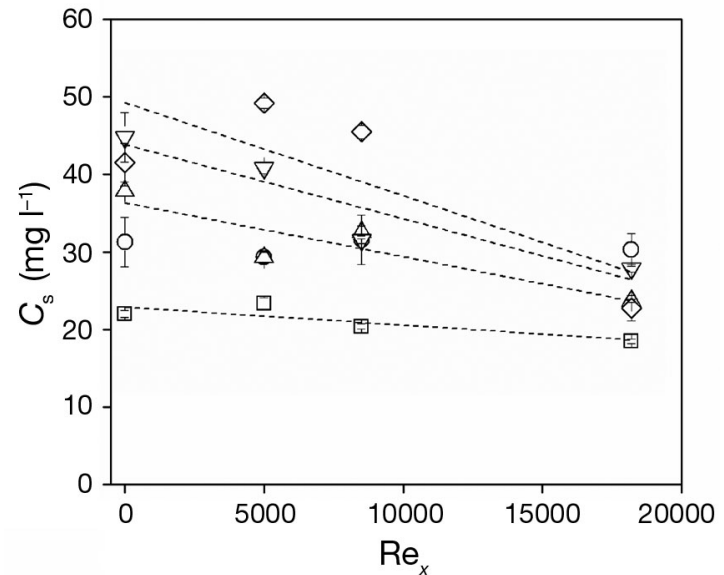

Fig. 4. Measured dissolved oxygen concentration, $C_{\mathrm{s}^{\prime}}$ on the surface of all kelp blades; 4 of the 5 replicates (different symbols) show a trend of $C_{\mathrm{s}}$ decreasing with $\mathrm{Re}_{\mathrm{x}}$. Error bars represent 1 standard deviation (SD) in the 60 measurements that were made for each data point

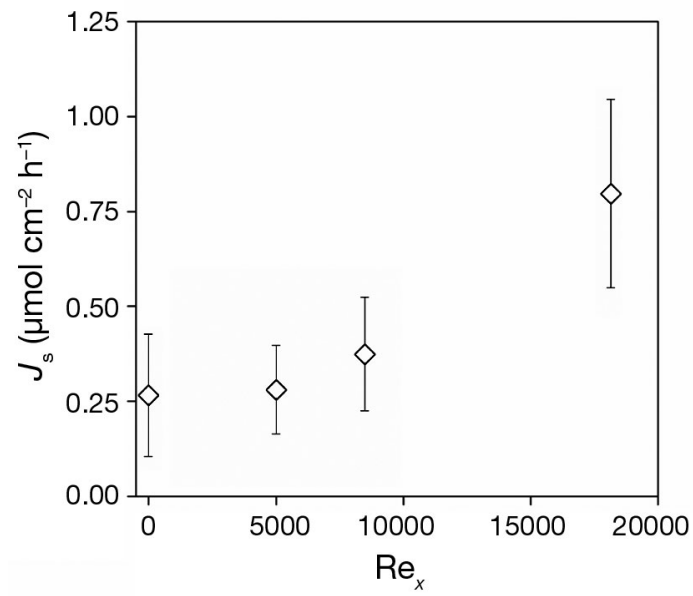

Fig. 5. Variation of local surface dissolved oxygen flux from the blade, $J_{\mathrm{s}}$ with $\mathrm{Re}_{x}$. Error bars represent $1 \mathrm{SD} ; 5$ replicates

significantly higher than the other $3 \operatorname{Re}_{x}$ conditions at $\mathrm{p}=0.05\left(q_{\text {critical }}=4.05\right)$. All other comparisons were not significant.

\section{Blade-averaged surface oxygen flux}

Eq. (9) was integrated numerically using a step size of $0.25 \mathrm{~cm}$ to determine the relationship of mass transfer velocity, $k\left(\mathrm{~cm} \mathrm{~s}^{-1}\right)$ to $u_{\infty}$, whereby $\bar{J}_{\mathrm{s} \text {,blade }}=k A_{\mathrm{s}}^{-1}$ $\left(C_{\mathrm{s}}-C_{\infty}\right.$ ) (Fig. 6). Implicit in this graph is the assumption that salinity equals $35 \mathrm{~g} \mathrm{l}^{-1}$ and the mathematical description of blade morphology $B(x)=\sqrt{\mathrm{x}}-0.1 \mathrm{x}$ for a blade of length $L=100 \mathrm{~cm}$. $B(x)$ was approximated by applying a nonlinear curve fit to the edge of a blade

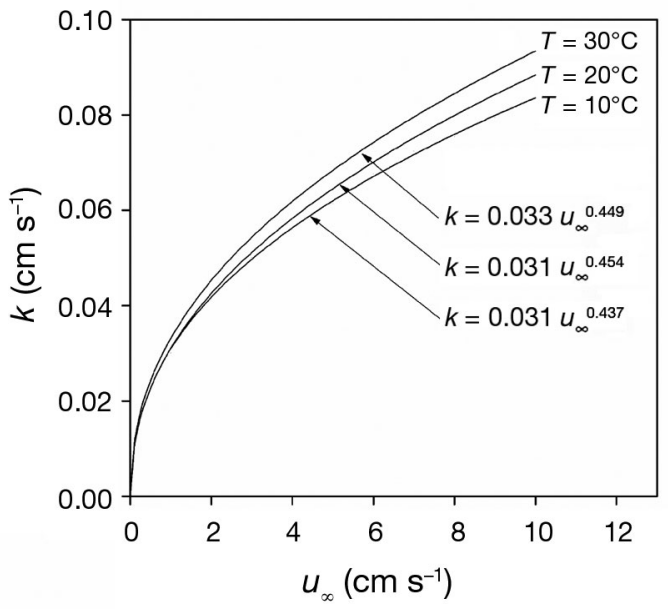

Fig. 6. Relationship between mass transfer velocity $k$ and $u_{\infty}$ for different water temperatures based on numerical solution of Eq. (9) and assumptions for blade morphology, $B(x)$ and $L$

from photographs of the experimental blades. $\bar{J}_{\text {s, blade }}$ was determined for each tested blade (Table 2) and was $60 \%$ higher, on average, at velocities that saturated the mass transfer limitation of photosynthesis than it was in stagnant water (Table 2).

\section{NPP estimate for entire kelp forest}

To illustrate the simplicity and validity of the derived model, we determined the forest-averaged daily NPP for the Mohawk Reef forest off the coast of Santa Barbara, California, USA, using reported data from November 2006 (Reed et al. 2008, Stewart et al. 2009). We chose data from November to match environmental conditions that affect $C_{\mathrm{s}}$, such as light availability and water temperature. The depth-averaged velocity measured in November 2006 within the Mohawk Reef kelp bed was $2.5 \mathrm{~cm} \mathrm{~s}^{-1}$ (Stewart et al. 2009). Using Fig. 6 this corresponds to a mass transfer velocity, $k$, of $0.035 \mathrm{~cm} \mathrm{~s}^{-1}$. The Mohawk Reef data set does not include measurements of $C_{\mathrm{s}}$ or $C_{\infty}$ i however, the reported November 2006 free-stream velocity of $2.5 \mathrm{~cm}$ $\mathrm{s}^{-1}$ is fairly close to one of the velocities at which we measured $C_{\mathrm{s}}$ and $C_{\infty}$ (tested $u_{\infty}=2.7 \mathrm{~cm} \mathrm{~s}^{-1}$ ), so we determined the average value of $C_{\mathrm{s}}-C_{\infty}$ from our data set to use for this estimation. This was $25 \mathrm{mg} \mathrm{l}^{-1}$ (Table $2 ; \mathrm{Re}_{x}=5000$ ). Assuming our blade morphology is typical for this location, the blade area is $332 \mathrm{~cm}^{2}$. We used a photosynthetic quotient of 1 (Arnold \& Manley 1985) to convert blade-averaged DO flux into bladeaveraged carbon dioxide $\left(\mathrm{CO}_{2}\right)$ flux. From the $\mathrm{CO}_{2}$ flux we could determine the molar carbon flux and convert that to grams of carbon per blade surface area per time 
(g C m${ }^{-2} \mathrm{~d}^{-1}$ ). This was converted to forest-averaged daily NPP using the reported blade density for November 2006 of $2 \mathrm{~m}^{2}$ blade area $\mathrm{m}^{-2}$ sea surface area (Stewart et al. 2009). The resulting estimate of forestaveraged daily NPP for November 2006 was $2.2 \mathrm{~g} \mathrm{C}$ $\mathrm{m}^{-2} \mathrm{~d}^{-1}$, the same value determined by Reed et al. (2008).

\section{DISCUSSION}

The proposed model can be used to predict local surface oxygen flux, $J_{\mathrm{s}}(x)$, blade-averaged surface oxygen flux, $\bar{J}_{\mathrm{s} \text {,blade, }}$ or forest-averaged daily NPP. The values for $u_{\infty}$ and $C_{\infty}$ are readily measured in the field or in a laboratory, and $C_{\mathrm{s}}$ is easily measured in a laboratory. For field experiments, $C_{\mathrm{s}}$ can be measured using either traditional oxygen microprobes with a custom length cable or a self-contained oxygen optode probe positioned by a diver on the surface of the blade. An alternative option is to use $C_{\mathrm{s}}$ measurements made in the laboratory to approximate in situ conditions, although, as Fig. 4 illustrates, flow can have as much influence on $C_{\mathrm{s}}$ as does overall blade physiology and must, therefore, be carefully replicated. The proposed model does not assume mass transfer limitation, but indirectly reflects other factors affecting photosynthesis, such as photon flux density (PFD), photo-adaptation, blade age, and blade health, in the measurement of $C_{\mathrm{s}}$. For 4 of the 5 blades tested, $C_{\mathrm{s}}$ decreased as $\mathrm{Re}_{\mathrm{x}}$ increased (Fig. 4), indicating some degree of mass transfer limitation. As velocities increase, transport of dissolved nutrients and waste products is more efficient, resulting in a lower $C_{\mathrm{s}}$. No functional dependency on $\mathrm{Re}_{x}$ was measured for Blade 7 , indicating that intracellular processes in the blade were limiting the rate of photosynthesis. For detailed laboratory studies examining local photosynthetic oxygen flux rates along individual blades, Eq. (7) can be directly applied with parametric determination from Fig. 3. There are no known measurements of local surface oxygen flux, so we cannot compare $J_{\mathrm{s}}(x)$ results to the literature.

To determine $\bar{J}_{\mathrm{s}, \text { blade }}$ or estimate entire forest NPP from in situ measurements of $u_{\infty}, C_{\infty}$ and $C_{\mathrm{s}}$ Eq. (7) can be integrated as shown in Eq. (9), or, if our assumed blade morphology is appropriate, Fig. 6 can be used to determine $k$ and then $\bar{J}_{\mathrm{s}, \text { blade }}=k A_{\mathrm{s}}^{-1}\left(C_{\mathrm{s}}-C_{\infty}\right)$. Since both $n$ and $a_{\mathrm{c}}$ are dependent on $x_{1}$ evaluating Eq. (9) analytically is difficult and numerical integration is recommended. $\bar{J}_{\mathrm{s}, \text { blade }}$ was found to range from $0.27 \mu \mathrm{mol} \mathrm{O}_{2} \mathrm{~cm}^{-2} \mathrm{~h}^{-1}$ for $\mathrm{Re}_{\mathrm{x}}=5000$ to $0.43 \mu \mathrm{mol} \mathrm{O}$ $\mathrm{cm}^{-2} \mathrm{~h}^{-1}$ for $\mathrm{Re}_{x}=18200$. The previously reported $\bar{J}_{\mathrm{s}, \text { blade }}$ for Macrocystis pyrifera under similar light and velocity conditions range from 0.3 to $2 \mu \mathrm{mol} \mathrm{O}_{2} \mathrm{~cm}^{-2} \mathrm{~h}^{-1}$ (Wheeler 1980, Gerard 1986, Colombo-Pallotta et al.
2006). Our blade-averaged fluxes agreed well with reported values at low $u_{\infty}$, but were lower than has been previously reported at high $u_{\infty}$. Although the PFD of $130 \mu \mathrm{mol} \mathrm{m} \mathrm{m}^{-2} \mathrm{~s}^{-1}$ in our experiment was chosen to match the results of Wheeler (1980), our water temperature was lower and may have slowed physiological processes in comparison to other laboratory studies. The free-stream velocity that saturates photosynthesis is dependent on conditions such as light level, freestream nutrient or carbon supply, and blade age or health and has been reported to be between 2 and $8 \mathrm{~cm} \mathrm{~s}^{-1}$ (Wheeler 1980, Gerard 1982, Hurd et al. 1996). The proposed model coupled with our experimental data showed an average saturation velocity of between 2 and $4 \mathrm{~cm} \mathrm{~s}^{-1}$ (Table 2).

The kelp forest averaged NPP estimates from the application of our model agreed with the NPP estimates generated by Reed et al. (2008), despite the numerous assumptions made in the application of our model. Although we chose data from Mohawk Reef in November to justify using our experimental results for $C_{\mathrm{S}}$, we could not match PFD values within the forest. PFD has been measured to be as high as $1200 \mu \mathrm{mol}$ photons $\mathrm{m}^{-2} \mathrm{~s}^{-1}$ on the water surface (Edwards \& Kim 2010), but has been shown to decay to $10 \%$ of the surface value by a depth of $1 \mathrm{~m}$ (Stewart et al. 2009). The depth-averaged PFD in a $30 \mathrm{~m}$ water column was calculated to be approximately $45 \mu \mathrm{mol}$ photons $\mathrm{m}^{-2} \mathrm{~s}^{-1}$. However, the biomass is typically greater near the surface, so the depth-averaged irradiance experienced by the kelp should be weighted by the vertical biomass distribution, and $130 \mu \mathrm{mol}$ photons $\mathrm{m}^{-2} \mathrm{~s}^{-1}$ may be more reasonable than it initially seems. Direct measurements of $C_{\mathrm{s}}$ at various depths could be used to assess this and to provide additional spatial resolution to the model. Variability of velocity with respect to position within the forest is available for Mohawk Reef (Gaylord et al. 2007) and could also be included to improve the model.

The appropriate time scale for estimating NPP with our model is on the order of a day. The Mohawk Reef kelp forest is reported to turn over 7 times per year (Reed et al. 2008); therefore, it is not reasonable to use our model to estimate annual NPP, since we do not take into account the effects of growth rate, recruitment, or disturbance history on NPP. It is equally inappropriate to use our model to estimate NPP for time scales of less than a day, since, on a shorter time scale, velocity fluctuations due to tides or internal waves can be significant and are not captured in our model. On a shorter time scale, the effective $u_{\infty}$ in a wavedominated environment may be higher than the measured $u_{\infty}$ due to relative motion between the blade and the water (Denny \& Roberson 2002, Stevens et al. 2003, Hepburn et al. 2007), and mass transfer limitation of 
photosynthesis would be saturated at lower velocities than the proposed model predicts.

The proposed model can be used to estimate local, blade-averaged, or forest-scale NPP in laminar, transitional, and turbulent flows. Developed from the classic engineering integral method, it provides a simple equation requiring minimal measurements and parameter determination. Being equally applicable in transitional flow regimes as in fully turbulent flow, the model accommodates the transitional flow characteristics that have been shown to be prevalent within kelp forests, yet are poorly matched by assumptions based on fully developed turbulent flow. To our knowledge, our model is the first that is applicable to all flow regimes, making it especially useful for the conditions commonly encountered within aquatic canopies such as kelp forests.

Acknowledgements. This work was supported by a travel grant to A.T.H. from the National Center for Earth-Surface Dynamics (NCED), a Science and Technology Center funded by the Office of Integrative Activities of the United States National Science Foundation (NSF) under Agreement EAR0120914 and Performance Based Research Funding (PBRF, Department of Botany) to C.L.H. The authors are grateful to Chris Hepburn, Daniel Pritchard, and Stewart Bell, Department of Botany, University of Otago, for assistance with kelp sample collection and the experimental setup. We also thank Jordan Theissen for his help with data acquisition.

\section{LITERATURE CITED}

Arnold KE, Manley SL (1985) Carbon allocation in Macrocystis pyrifera (Phaeophyta): intrinsic variability in photosynthesis and respiration. J Phycol 21:154-167

Bird RB, Stewart WE, Lightfoot EN (2002) Transport phenomena, 2nd edn. John Wiley \& Sons, Inc., New York, NY

Burmeister LC (1993) Convective heat transfer, 2nd edn. John Wiley \& Sons, Inc., New York, NY

> Colombo-Pallotta MF, Garcia-Mendoza E, Ladah LB (2006) Photosynthetic performance, light absorption, and pigment composition of Macrocystis pyrifera (Laminariales, Phaeophyceae) blades from different depths. J Phycol 42: 1225-1234

Cornelisen CD, Thomas FIM (2009) Prediction and validation of flow-dependent uptake of ammonium over a seagrasshardbottom community in Florida Bay. Mar Ecol Prog Ser 386:71-81

Cussler EL (1984) Diffusion: mass transfer in fluid systems. Cambridge University Press, New York, NY

> Dayton PK (1985) Ecology of kelp communities. Annu Rev Ecol Syst 16:215-245

> Denny M, Roberson L (2002) Blade motion and nutrient flux to the kelp, Eisenia arborea. Biol Bull 203:1-13

Edwards MS, Kim KY (2010) Diurnal variation in relative photosynthetic performance in giant kelp Macrocystis pyrifera (Phaeophyceae, Laminariales) at different depths as estimated using PAM fluorometry. Aquat Bot 92:119-128

Enriquez S, Rodriguez-Roman A (2006) Effect of water flow on the photosynthesis of three marine macrophytes from a fringing reef lagoon. Mar Ecol Prog Ser 323:119-132
Falter JL, Atkinson MJ, Merrifield MA (2004) Mass transfer limitation of nutrient uptake by a wave dominated reef flat community. Limnol Oceanogr 49:1820-1831

Fram JP, Stewart HL, Brzezinski MA, Gaylord B, Reed DC, Williams SL, MacIntyre S (2008) Physical pathways and utilization of nitrate supply to the giant kelp, Macrocystis pyrifera. Limnol Oceanogr 53:1589-1603

Gaylord B, Reed DC, Washburn L, Raimondi PT (2004) Physical-biological coupling in spore dispersal of kelp forest macroalgae. J Mar Syst 49:19-39

Gaylord B, Rosman JH, Reed DC, Koseff JR and others (2007) Spatial patterns of flow and their modification within and around a giant kelp forest. Limnol Oceanogr 52: 1838-1852

- Gerard VA (1982) In situ water motion and nutrient-uptake by the giant kelp Macrocystis pyrifera. Mar Biol 69:51-54

Gerard VA (1986) Photosynthetic characteristics of giant kelp (Macrocystis pyrifera) determined in situ. Mar Biol 90: 473-482

> Gonen Y, Kimmel E, Friedlander M (1993) Effect of relative water motion on photosynthetic rate of red alga Gracilaria conferta. Hydrobiologia 260/261:493-498

Graham MH, Vasquez JA, Buschmann AH (2007) Global ecology of the giant kelp Macrocystis: from ecotypes to ecosystems. Oceanogr Mar Biol Annu Rev 45:39-88

Hepburn CD, Hurd CL (2005) Conditional mutualism between the giant kelp Macrocystis pyrifera and colonial epifauna. Mar Ecol Prog Ser 302:37-48

> Hepburn CD, Holborow JD, Wing SR, Frew RD, Hurd CL (2007) Exposure to waves enhances the growth rate and nitrogen status of the giant kelp Macrocystis pyrifera. Mar Ecol Prog Ser 339:99-108

Hondzo M, Feyaerts T, Donovan R, O'Connor BL (2005) Universal scaling of dissolved oxygen distribution at the sediment-water interface: a power law. Limnol Oceanogr 50: 1667-1676

> Hurd CL (2000) Water motion, marine macroalgal physiology, and production. J Phycol 36:453-472

Hurd CL, Pilditch CA (2011) Flow induced morphological variations affect boundary-layer thickness of Macrocystis pyrifera (Heterokontophyta, Laminariales). J Phycol 47: $341-351$

> Hurd CL, Stevens CL (1997) Flow visualization around single and multiple bladed seaweeds with various morphologies. J Phycol 33:360-367

- Hurd CL, Quick M, Stevens CL, Laval BE, Harrison PJ, Druehl LD (1994) A low volume flow tank for measuring nutrient uptake by large macrophytes. J Phycol 30: 892-896

> Hurd CL, Harrison PJ, Druehl LD (1996) Effect of seawater velocity on inorganic nitrogen uptake by morphologically distinct forms of Macrocystis integrifolia from wave-sheltered and exposed sites. Mar Biol 126:205-214

> Jackson GA (1977) Nutrients and production of giant kelp, Macrocystis pyrifera, off southern California. Limnol Oceanogr 22:979-995

Kays W, Crawford M, Weigand B (2005) Convective heat and mass transfer, 4th edn. McGraw-Hill, Boston, MA

Koch EW (1994) Hydrodynamics, diffusion boundary layers and photosynthesis of the seagrasses Thalassia testudinum and Cymodocea nodosa. Mar Biol 118:767-776

Longstaff BJ, Kildea T, Runcie JW, Cheshire A and others (2002) An in situ study of photosynthetic oxygen exchange and electron transport rate in the marine macroalga Ulva lactuca (Chlorophyta). Photosynth Res 74:281-293

> Maberly SC (1990) Exogenous sources of inorganic carbon for photosynthesis by marine macroalgae. J Phycol 26:439-449 
Mass T, Genin A, Shavit U, Grinstein M, Tchernov D (2010) Flow enhances photosynthesis in marine benthic autotrophs by increasing the efflux of oxygen from the organism to the water. Proc Natl Acad Sci USA 107:2527-2531

Maxwell K, Johnson GN (2000) Chlorophyll fluorescence-a practical guide. J Exp Bot 51:659-668

Miller HL, Dunton KH (2007) Stable isotope $\left({ }^{13} \mathrm{C}\right)$ and $\mathrm{O}_{2}$ micro-optode alternatives for measuring photosynthesis in seaweeds. Mar Ecol Prog Ser 329:85-97

Nezu I, Rodi W (1986) Open-channel flow measurements with a laser Doppler anemometer. J Hydraul Eng 112:335-355

Nishihara GN, Ackerman JD (2006) The effect of hydrodynamics on the mass transfer of dissolved inorganic carbon to the freshwater macrophyte Vallisneria americana. Limnol Oceanogr 51:2734-2745

Nishihara GN, Ackerman JD (2007) On the determination of mass transfer in a concentration boundary layer. Limnol Oceanogr Meth 5:88-96

Reed DC, Rassweiler A, Arkema KK (2008) Biomass rather than growth rate determines variation in net primary production by giant kelp. Ecology 89:2493-2505

Rosman JH, Koseff JR, Monismith SG, Grover J (2007) A field investigation into the effects of a kelp forest (Macrocystis pyrifera) on coastal hydrodynamics and transport. J Geophys Res C 112:C02016

Sand-Jensen K, Revsbech NP, Jorgensen BB (1985) Micropro- files of oxygen in epiphyte communities on submerged macrophytes. Mar Biol 89:55-62

Sanford LP, Crawford SM (2000) Mass transfer versus kinetic control of uptake across solid-water boundaries. Limnol Oceanogr 45:1180-1186

Schlichting H (1979) Boundary-layer theory, 7th edn. McGraw-Hill, New York, NY

Steneck RS, Graham MH, Bourque BJ, Corbett D, Erlandson JM, Estes JA, Tegner MJ (2002) Kelp forest ecosystems: biodiversity, stability, resilience and future. Environ Conserv 29:436-459

Stevens CL, Hurd CL, Isachsen PE (2003) Modelling of diffusion boundary layers in subtidal macroalgal canopies: the response to waves and currents. Aquat Sci 65:81-91

Stewart HL, Fram JP, Reed DC, Williams SL, Brzezinski MA, MacIntyre S, Gaylord B (2009) Differences in growth, morphology and tissue carbon and nitrogen of Macrocystis pyrifera within and at the outer edge of a giant kelp forest in California, USA. Mar Ecol Prog Ser 375:101-112

Wheeler WN (1980) Effect of boundary-layer transport on the fixation of carbon by the giant kelp Macrocystis pyrifera. Mar Biol 56:103-110

Zimmerman RC, Kremer JN (1986) In situ growth and chemical composition of the giant kelp, Macrocystis pyriferaresponse to temporal changes in ambient nutrient availability. Mar Ecol Prog Ser 27:277-285

Appendix 1. Detailed model derivation

Assuming a unidirectional flow and that the kelp blade behaves as a flat smooth plate, conservation of momentum in integral form is:

$$
-\tau_{s}=\frac{\mathrm{d}}{\mathrm{d} x}\left(\int_{0}^{\delta} \rho u^{2} \mathrm{~d} y\right)-u_{\infty} \frac{\mathrm{d}}{\mathrm{d} x}\left(\int_{0}^{\delta} \rho u \mathrm{~d} y\right)
$$

In integral form, the conservation of DO mass is:

$$
J_{s}=\frac{\mathrm{d}}{\mathrm{d} x}\left(\int_{0}^{\Delta} \rho u\left(C-C_{\infty}\right) \mathrm{d} y\right)
$$

The velocity profile in the momentum boundary layer was modeled with a power function:

$$
\frac{u}{u_{\infty}}=\left(\frac{y}{\delta}\right)^{1 / n}
$$

where $n$ is a constant. The dimensionless concentration profile can also be modeled with a power function:

$$
\frac{C_{s}-C(y)}{C_{s}-C_{\infty}}=\left(\frac{y}{\Delta}\right)^{1 / n}
$$

We evaluated the momentum equation to determine $\delta$ as a function of $x$ and the relationship of $\tau_{\mathrm{s}}$ to $\operatorname{Re}_{x}$, where $\operatorname{Re}_{x}=$ $u_{\infty} x / v$. The right side of Eq. (1) was integrated from zero to $\delta$ after substitution of the power function (Eq. 3). This results in the expression:

$$
\frac{\tau_{s}}{\rho u_{\infty}^{2}}=\left(\frac{n}{n+1}-\frac{n}{n+2}\right) \frac{\mathrm{d} \delta}{\mathrm{d} x}
$$

To evaluate $\tau_{\mathrm{s}}$, we wrote Eq. (3) in terms of the commonly used dimensionless variables $u^{+}$and $y^{+}$, where $u^{+}=u u_{*}^{-1}$, $y^{+}=y u_{*} v^{-1}$, and rearranged it to the form:

$$
u^{+}=a_{c}\left(y^{+}\right)^{1 / n}
$$

where $a_{\mathrm{c}}=\left(u_{\infty} u_{*}^{-1}\right)\left[v\left(u_{*} \delta\right)^{-1}\right]^{1 / n}$, and is typically treated as an empirical constant (Schlichting 1979). Substituting $\sqrt{\tau_{\mathrm{s}} / \rho}$ into Eq. (5) and evaluating it at $\delta, \tau_{\mathrm{s}}$ was determined as a function of $\delta$ :

$$
\frac{\tau_{s}}{\rho u_{\infty}^{2}}=a_{c}^{\left(\frac{-2 n}{n+1}\right)}\left(\frac{u_{\infty} \delta}{v}\right)^{\left(\frac{-2}{n+1}\right)}
$$

Substituting the expression for surface shear stress provided in Eq. (A2) into Eq. (A1), separating terms, and integrating, we determined the relationship between $\delta$ and $x$ :

$$
\delta(x)=\frac{(n+2)(n+3)}{n} A \operatorname{Re}_{x}^{-\left(\frac{2}{n+3}\right)} X
$$

where $A$ is the constant given in Eq. (8). Substituting Eq. (A3) into Eq. (A1) provides a dimensionless expression relating the local coefficient of friction, $C_{\mathrm{f}}$, to $\mathrm{Re}_{\mathrm{X}}$ :

$$
\frac{C_{\mathrm{f}}}{2}=\frac{\tau_{s}}{\rho u_{\infty}^{2}}=A \operatorname{Re}_{X}^{-\left(\frac{2}{n+3}\right)}
$$

To evaluate the conservation of mass given in Eq. (2), we substituted the velocity and concentration profiles (Eqs. 3 \& 4), integrated, and obtained: 
Appendix 1 (continued)

$$
\frac{J_{s}}{u_{\infty}\left(C_{s}-C_{\infty}\right)}=\frac{\mathrm{d}}{\mathrm{d} x}\left(\Delta\left(\frac{\Delta}{\delta}\right)^{\frac{1}{n}}\right)
$$

To determine $J_{\mathrm{s}}$, we followed the procedure developed by Reynolds (Kays et al. 2005). Briefly, the integral form of the momentum equation is developed for a control volume extending from an arbitrary distance at or above the blade surface, $y$, to the outer limit of the boundary layer, $\delta$. The resulting form of the momentum integral equation is:

$$
-\tau_{y}=\frac{\mathrm{d}}{\mathrm{d} x} \int_{y}^{\delta} \rho u^{2} \mathrm{~d} y-\rho v_{\delta} u_{\infty}-\rho v_{y} u_{y}
$$

The ratio of Eq. (A6) evaluated at $y=y$, to Eq. (A6) evaluated at $y=0$, using the velocity power function approximation from Eq. (3) resulted in:

$$
\frac{\tau_{y}}{\tau_{s}}=1-\left(\frac{y}{\delta}\right)^{\left(\frac{n+2}{n}\right)}
$$

Combining Eq. (A7) with the mixing layer analogy of shear stress in a turbulent flow $\tau / \rho=\left[v+\varepsilon_{\mathrm{m}}\right] \partial \mathrm{u} / \partial \mathrm{y}$ and solving for $\left[v+\varepsilon_{m}\right]$, we obtained:

$$
\left[v+\varepsilon_{m}\right]=n v \frac{C_{\mathrm{f}}}{2}\left(\frac{\delta}{x}\right) \operatorname{Re}_{x}\left[1-\left(\frac{y}{\delta}\right)^{\left(\frac{n+2}{n}\right)}\right]\left(\frac{y}{\delta}\right)^{\left(\frac{n-1}{n}\right)}
$$

Using the approximation $S_{C_{\mathrm{T}}} \approx 1$ for high $S_{C}$ fluids (Bird et al. 2002, Kays et al. 2005) and that within the concentration boundary layer $v>>\varepsilon_{m}$, the sum of the molecular diffusion coefficient $D\left(\mathrm{~m}^{2} \mathrm{~s}^{-1}\right)$ and $D_{\mathrm{T}}$ can be expressed in terms of $\left[v+\varepsilon_{\mathrm{m}}\right]$ as:

$$
\left[D+D_{\mathrm{T}}\right] \approx S C^{-1}\left[v+\varepsilon_{m}\right]
$$

Using Fick's First Law:

$$
J=-\left[D+D_{T}\right] \frac{\partial C}{\partial y}
$$

and evaluating the product of the derivative of Eq. (4) and Eq. (A8) in Eq. (6) for $y=0$, the surface DO flux, $J_{\mathrm{s}}$ is:

$$
J_{s}=S C^{-1} \frac{\tau_{s}}{\rho u_{\infty}^{2}} u_{\infty}\left(\frac{\Delta}{\delta}\right)^{-\left(\frac{1}{n}\right)}\left(C_{s}-C_{\infty}\right)
$$

Substituting Eq. (A1) into Eq. (A10) and Eq. (A10) into Eq. (A5) and integrating from 0 to $x$, we derived an expression for the ratio of the 2 boundary layers:

$$
\frac{\Delta}{\delta}=\left(S C^{-1}\left(1-\delta^{\left(\frac{n+2}{n+1}\right)}\right)\right)^{\left(\frac{n}{n+2}\right)}
$$

Eq. (A11) can be expressed in terms of $x$ from the expression for $\delta(x)$ given in Eq. (A3). then substituted into Eq. (A10), to arrive at the final expression for kelp surface DO flux:

$$
J_{S}(x)=A S C^{-\left(\frac{n+1}{n+2}\right)} \operatorname{Re}_{x}^{-\left(\frac{2}{n+3}\right)} u_{\infty}\left(C_{s}-C_{\infty}\right)
$$

Editorial responsibility: Matthias Seaman, Oldendorf/Luhe, Germany
Submitted: October 7, 2010; Accepted: May 4, 2011 Proofs received from author(s): July 17, 2011 